\title{
Economic Load Dispatch with Valve-point Effect Using Bacterial Foraging Algorithm
}

\author{
Muhammad Ridha Fauzi ${ }^{\star 1}$, Rahmad Al Rian ${ }^{2}$ \\ ${ }^{1}$ Faculty of Engineering, Muhammadiyah University of Riau, Jl. KH. Ahmad Dahlan No. 88 Pekanbaru, \\ telp/fax(0761) 35008, Indonesia \\ ${ }^{2}$ Faculty of Teacher Training and Education, Muhammadiyah University of Riau, Jl. KH. Ahmad Dahlan \\ No. 88 Pekanbaru, telp/fax(0761) 35008, Indonesia \\ *Corresponding author, e-mail: mridhafauzi@umri.ac.id
}

\begin{abstract}
Fuel is the most cost component of thermal power generation. The output power of each plant should not exceed the needs of the consumer's load. Unoptimal generation between generating units can cause power losses along the transmission line so that the fuel drain is large enough. The purpose of this study was to determine the optimal power output combination of each generating unit and determine the minimum total fuel cost of the combined power output of the plant by taking into account the valve-point effect and the operational constraint (economic load dispatch). The Newton-Raphson method is used to calculate the transmission line power losses. In this research, Bacterial Foraging Algorithm (BFA) optimization method is proposed to solve the problem of economic load dispatch. This method uses natural selection of optimum global bacterium which has a good food search strategy in the fitness function. The effectiveness of BFAs is tested on IEEE 5 bus 3 generatorsystem and IEEE 30 bus 6 generator system. The results of this proposed method show the optimal value of both generating systems.
\end{abstract}

Keywords: economic load dispatch, valve-point effect, fuel cost, bacterial foraging algorithm

Copyright (C 2018 Universitas Ahmad Dahlan. All rights reserved.

\section{Introduction}

Economic load dispatch is a very important problem in planning power generation that aims to determine the combination of the output power of each generation unit so as to produce the minimum generation cost by considering the operational constraint and the load supply. Economic load dispatch problems is very difficult to solve mathematically because it has nonlinear characteristics, especially when involvinglarge generating units are inherently very non-linear due to the valve-point loading effect and also generate multiple local minimum points in the cost function.

Several attempts to resolve the economic load dispatch problems have been done. Many methods have been used to solve economic load dispatch problems such as lambdaiteration methods, base point and participation factors and gradient methods. These methods can not solve the problems because the cost functionsare non-linear. Therefore, in recent years, researchers have applied smart methods to solve the problem.

In reference [1], the dynamic programming method has applied to solve economic load dispatch problems that has no natural limitations of the cost curve. This can result in a global solution even for the non-linear and discrete cost curves of the generation units [1]. Furthermore, [2] incorporates the hybrid method of Genetic Algorithm-Pattern SearchSequential Quadratic Programming (GA-PS-SQP) and proved the proposed method results in good performance as well.

In the references [3], [4], and [5] each researcher has applied Particle Swarm Optimization Algorithm, Chaos-Enhanced Cuckoo Search, and Bee Colony Optimization methods to solve economic dispath problems.

In this research the Bacterial Foraging Algorithm method is proposed to solve economic dispatch problem. To obtain more real economic dispatch values, the valve-point effect component is considered in this issue. The effectiveness of the proposed algorithm is then Bacterial Foraging Algorithmis tested on IEEE 5 bus 3 generator system and IEEE 30 bus 6 generator system. 


\subsection{Problem Formulation}

The input-output-generating characteristics of the generating unit, the generated output power is limited by the minimum and maximum capacity of the generating unit, namely [4]:

$$
P_{\mathrm{G} \min } \leq P_{\mathrm{G}} \leq P_{\mathrm{G} \max }
$$

The input-output characteristic of the generator is nonlinear ie quadratic function:

$$
F=a+b P_{G}+c P_{G}^{2}
$$

with $a, b$, and $c$ are the input-output characteristic coefficients. Constanta $a$ is equivalent to the fuel consumption of the generating unit without output power. The problem of economic loading dispatch can be defined as the fuel cost optimization problem. The objective function of the fuel is $[3,6]$ :

$$
\operatorname{Minimize} F\left(P_{g}\right)=\sum_{i=1}^{m} a_{i}+b_{i} P_{g i}+c_{i} P_{g i}^{2}
$$

where $F$ is the fuel cost in $\$ / \mathrm{h}$, Pgi is the real power generated by $i, a_{i}, b_{i}$, and $c_{i}$ generators is the fuel cost coefficient of the $i$-generation unit. The total number of generators in operation. Based on the operational requirements, the minimization of the objective function must follow the following constraints:

a. Power balance constraint atau demand constraint

Total power generation $\sum_{i=1}^{m}\left(P_{g i}\right)$ should be able to cover or equal to total demand of $P_{D}$ system plus real power loss $P_{\text {LosS }}$ transmission system:

$$
\sum_{i=1}^{m}\left(P_{g i}\right)=P_{D}+P_{L O S S}
$$

b. Low and up limitoutput generator constraint

The output power of each generator must be limited between the minimum and maximum (inequality constraint) limits for which the boiler can operate stable. The inequality constraint is [7], [8]:

$$
P_{\mathrm{gi}}{ }^{\mathrm{min}} \leq P_{\mathrm{gi}} \leq P_{\mathrm{gi}}{ }^{\max }
$$

$P_{g i}$ is the real power output of the generator to $i$ and, is the real power of the minimum and maximum output of the generator to $i$.

\subsection{Economic Dispatch by Taking into Account Valve-Point Effect}

The fuel cost function model in (3) above can be modified more rationally and precisely. Generating units with multi-valve steam turbines show greater variation in fuel cost functions. The multi valve steam turbine valve opening process produces a ripple effect such as the generator heat rate curve. Valve-point loading effect is illustrated in Figure 1 [9].

The significance of this effect is that the function of the large steam generating cost curve is in fact not continuous but more importantly nonlinear. In fact, generating units with multi-valve steam turbines have very different input-output curves compared to smooth charge functions. Therefore, the inclusion of the valve-point loading effect makes the representation of additional fuel cost functions of generating units more practical. The additional fuel cost function of the generating unit with a valve-point loading effect is represented as follows [5, 10]:

$$
f_{i}\left(P_{g i}\right)=a_{i}+b_{i} P_{g i}+C_{i} P_{g i}^{2}+\left|e_{i} \sin \left(f_{i}\left(P \underset{g i}{\min }-P_{g i}\right)\right)\right|
$$


Where $e_{i}$ and $f_{i}$ are generator coefficients that reflect valve-point effects.

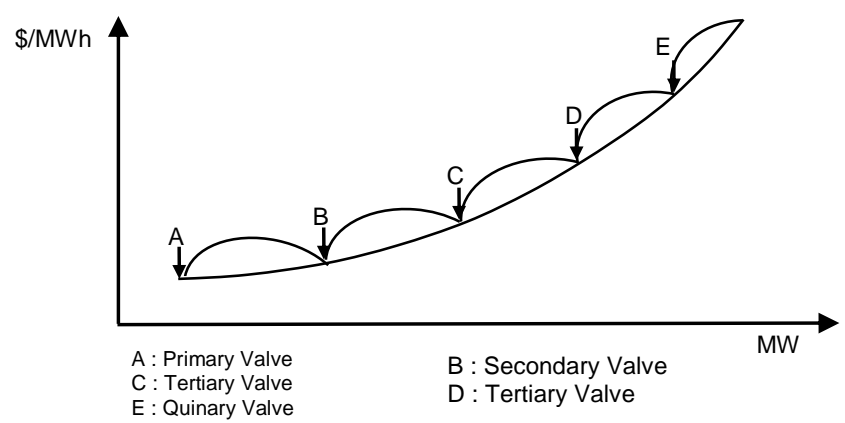

Figure 1. Characteristics of generators with valve point loading effect

\subsection{Bacterial Foraging Algorithm}

\subsubsection{Bacterial Eschericia Coli}

Escherichia coli (E. coli) bacteria have plasma membranes, cell walls, and capsules containing nucleoids and cytoplasm.Pili (single, pilus), and flagella (single, flagelline) are used to move. E. coli bacteria is shown in Figure 2.

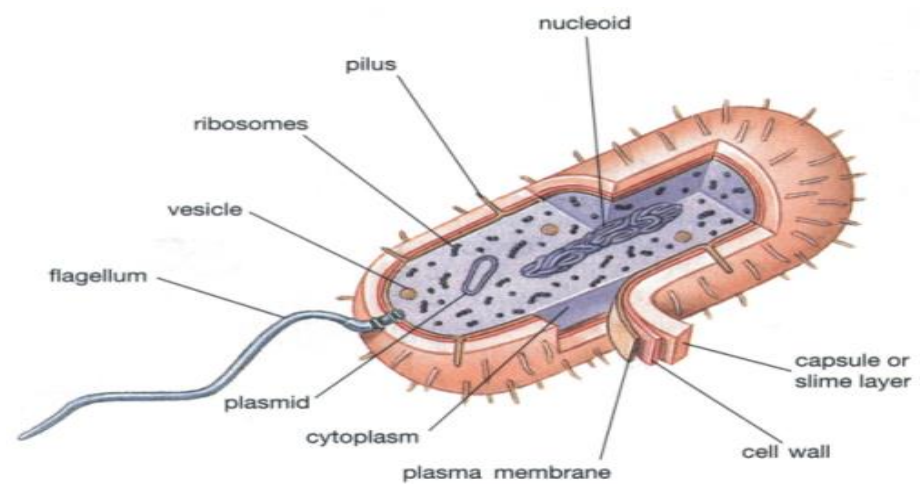

Figure 2. E. Coli Bacteria [11]

\subsubsection{Swimming and Tumbling via Flagella [12]}

Flagella is a tool used by bacteria to move so that bacteria can swim (swim) through rotary flagella in the same direction around 100-200 revolutions per second. E. Coli bacteria can move in two different ways, keep a run (swim for a period of time) or tumble, and switch between two lifelong operating modes (flagella rarely stops spinning). If the flagellar rotates clockwise, each channel draws the cell, and the effect is that each flagella operates relatively free of the other, so the "Tumble" bacteria (ie, bacteria have no direction of movement and there is slight displacement) as shown in Figure 3 (a). To tumble after run, the cell moves slow or first stops; because the bacteria are so small, they barely experience the inertia, only the viscosity, so when the bacteria stops the swim, it stops in the diameter of the proton. After the tumble, generally the cell will lead to random directions, but there is a slight bias toward the journey before tumble.

If the flagella moves counter-clockwise, the effect of flagella makes a combined propeller and encourages bacteria to run (swim) in one direction as shown in Figure 3 (a) above. The bacteria motion pattern generates chemical attractant and reflux (refuse) called chemotaxes. The resulting pattern of E. coli bacteria behavior generally they try to find food and avoid dangerous phenomena. 
If $\mathrm{E}$. Coli is in a neutral substance (no food or hazardous substance) for a long time (for example, more than $1 \mathrm{~min}$ ), then flags together alternately between clockwise and counter clockwise moves so that the bacteria will alternately tumble and run. Replace between two modes this causes the bacteria to move, but to the random direction, and it is possible to look for nutrients as shown in Figure 3 (b). The basic behavior of search is though bacteria have food, but bacteria keep searching for more.

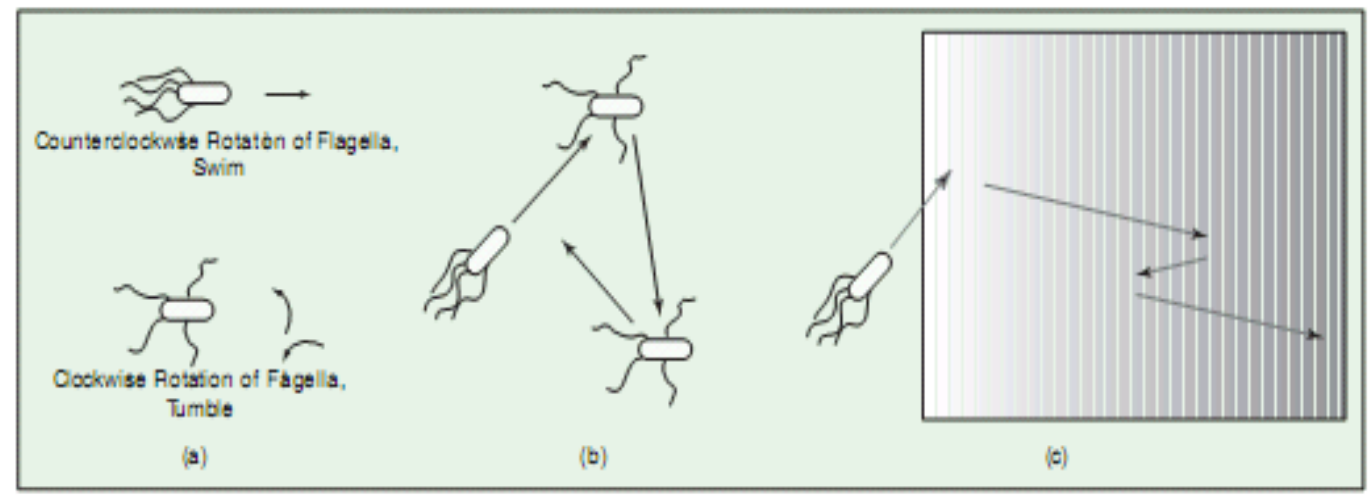

Figure 3. Behavior swimming (a), tumbling (b), and chemotactic (c) bakteri E. Coli

Next, Figure 3 (c) shows if the bacteria are in the nutrient feedstock (eg, serine). Changes in nutrient concentration trigger reactions such that the bacteria will spend more time for swimming and less for tumbling. As long as the bacteria run at a positive gradient concentration (eg, the bacteria move toward increased nutritional concentration) the bacteria will tend to extend the time for swimming (bacteria run further), to a point. The direction of movement is "biased" towards an increase in the nutrient gradient. The cell does not change its direction on the run because the gradient-tumble change basically determines the direction of run, apart from the Brownian influence mentioned above.

E. Coli bacteria present in our intestines have a feeding strategy built by four processes: chemotaxis, swarming, reproduction, and elimination and dispersal.

a. Chemotaxis

The Chemotaxis process is achieved through swimmning and tumbling, depending on the rotation of flagella on each bacterium. It decides whether the bacteria should move in a predetermined direction (swimmning) or a completely different direction (tumbling) across the life time of the bacteria. To represent a tumble, a unit length of random (random) direction is generated $f(j)$. Unit length is used to determine the direction of movement after the tumble. The bacterial position after the next chemotactic step is expressed by,

$$
\dot{\theta}(j+1, k, l)=\dot{\theta}(j, k, l)+C(I) \phi(j)
$$

With $\dot{\theta}(j, k, I)$ denoting the position of the $i$-th bacteria in the $S$ bacterial population on the $j$-th chemotactic step, the $k$-step reproduction, and the elimination and the step-l. step dispersal $C(i)$ is the step size taken in the direction random and expressed by tumble. " $C$ " is termed "run length unit."

b. Swarming

In a group, bacteria that have found the optimal food should try to attract other bacteria so that they reach the desired spot faster with constructive cooperation. With swarming, the bacteria gather in groups and therefore move like group concentric patterns with high bacterial density. Mathematically can be expressed by

$$
J_{c c}(\theta, P(j, k, l))=\sum_{i=1}^{s} J_{c c}^{i}\left(\theta, \theta^{i}(j, k, l)\right)
$$




$$
\begin{aligned}
& =\sum_{i=1}^{S}\left[-d_{\text {attract }} \exp \left(-\omega_{\text {attract }} \sum_{m=1}^{p}\left(\theta_{m}-\theta_{m}^{i}\right)^{2}\right)\right] \\
& +\sum_{i=1}^{S}\left[h_{\text {repellant }} \exp \left(-\omega_{\text {repellant }} \sum_{m=1}^{p}\left(\theta_{m}-\theta_{m}^{i}\right)^{2}\right)\right]
\end{aligned}
$$

with $\theta=\left[\theta_{1}, \ldots \theta_{\mathrm{p}}\right]^{\top}$ is a point on the optimization domain and $\theta_{m}^{i}$ is the mth component of the $i$-th bacteria position, $\dot{\theta}=P$. $J_{c C}(\theta, P(j, k, I))$ is the value of the cost function added to the actual cost function that will be minimized to illustrate the cost function of various times. " $S$ " is the total number of bacteria and " $p "$ is the number of parameters to be optimized contained in each bacteria. $D_{\text {attract }}, x_{\text {attract }}, h_{\text {repelent, }}$ and $\omega_{\text {repelent }}$ is a different coefficient that will be chosen wisely.

c. Reproduction

After the chemotaxis process, the most unhealthy bacteria will die and the other healthy bacteria each split into two bacteria, which are placed in the same location. This makes the bacterial population constant.

d. Elimination and Dispersal

The life of the bacterial population may change gradually both because of the sudden consumption of nutrients and other effects in the local environment. This event can cause all bacteria at a location to be killed or a group of bacteria can be spread to a new part of the environment. They have an effect that may destroy chemotactic progress, but on the contrary, they also help, because dispersal can put bacteria close to a good food source. Elimination and dispersal help in reducing the local premature or optimal solution point.

\section{Research Method}

At this stage will be simulated for some cases with some electrical systems are:

\subsection{Economic Load Dispatch Takes Into Account Transmission Losses}

In this case, the effectiveness of BFAs is tested on two electrical systems. The simulation process starts from:

a. Input data

The input data is the minimum and maximum output power of each generator, the equation of the input-output characteristic (cost function) as an objective function.

b. Initialization

At the initialization stage, each Sbacteria represents one possible solution candidate from the economic dispatch problem.

c. Chemotaxis

d. Reproduction

e. Elimination and Dispersal

\subsection{Economic Load Dispatch with Valve-Point Effect Taking Into Account the} Transmission Loss

The computational steps in this case are as follows:

a. Input data in the form of the minimum and maximum output power of each generator, the equation of the input-output characteristics of the generator (cost function) with the valvepoint effect as an objective function.

b. Initialization of BFA parameter consists of search space dimension or number of parameters to be optimized $(p)$, number of bacteria $(S)$, length of swimming $(N s)$, number of Chemot axis loop or length of life of bacteria $(\mathrm{Nc})$, number of reproduction loop (Nre) Elimination-dispersal loop $(N e d)$, elimination-dispersal probability $(P e d)$, runlength unit or step size $(C(I))$, value of signal attractant depth that is released $\left(d_{\text {attract }}\right)$, wide attractant signal $\left(w_{\text {attract }}\right)$, high repellant effect $\left(h_{\text {repellant }}\right)$, wide repellant $\left(w_{\text {repellant }}\right)$.

c. From existing data of each generator then Ploss power loss is calculated using power flow analysis for the first time before the optimization using BFA.

d. Optimization of economic dispatch with valve-pont effect using BFA. 
e. If the iteration termination criterion has not been met then the calculation goes back to step 3.

f. The solution obtained from the above process, the best position of the bacteria representing the optimal combination of the generator's output power is fed into the load flow to obtain the loss value of the transmission power. Finally, the minimum generation cost is obtained from all combinations of plants.

\section{Results and Analysis}

In this section the Bacterial Foraging Algorithm was applied to two cases to solve the economic dispatch problem. One case is an economic dispatch problem with no valve-point effect and one more case of economic dispatch with valve-point effect. This economic dispatch problem considers the loss of transmission line power.

The effectiveness of Bacterial Foraging Algorithm was applied to two test systems ie IEEE 5 bus 3 generating system $\left(P_{D}=150 \mathrm{MW}\right)$, and IEEE 30 bus 6 generating system $\left(P_{D}=\right.$ 283.4 MW). The fuel cost coefficient data, valve-point effect coefficients on the IEEE 5 bus 3 generator system [13] are shown in Table 1 to Table 2 and the IEEE system 30 bus 6 generator [14] is shown in Table 3 to Table 4. Simulation results for both systems are shown in Table 5 to Table 6.

Table 1. Low and Up Power Limit, Fuel Cost Coefficient of the IEEE 5 Bus 3 Generating System

\begin{tabular}{cccccc}
\hline Unit & $\begin{array}{c}P \min \\
(\mathrm{MW})\end{array}$ & $\begin{array}{c}P \max \\
(\mathrm{MW})\end{array}$ & $a_{i}$ & $b_{i}$ & $c_{i}$ \\
\hline 1 & 10 & 85 & 200 & 7 & 0,008 \\
2 & 10 & 80 & 180 & 6,3 & 0,009 \\
3 & 10 & 70 & 140 & 6,8 & 0,007 \\
\hline
\end{tabular}

Table 2. Valve-point Effect Coefficient Data of IEEE 5 Bus 3 Generating System

\begin{tabular}{ccc}
\hline Unit & $d_{i}$ & $e_{i}$ \\
\hline 1 & 300 & 0,0315 \\
2 & 200 & 0,042 \\
3 & 150 & 0,063 \\
\hline
\end{tabular}

Table 3. Data of Low and Up power limit, fuel cost coefficient of IEEE 30 Bus 6 Generating System

\begin{tabular}{cccccc}
\hline Unit & $\begin{array}{c}P \min \\
(\mathrm{MW})\end{array}$ & $\begin{array}{c}P \max \\
(\mathrm{MW})\end{array}$ & $a_{i}$ & $b_{i}$ & $c_{i}$ \\
\hline 1 & 50 & 200 & 0 & 2 & 0,00375 \\
2 & 20 & 80 & 0 & 1,75 & 0,01750 \\
3 & 15 & 50 & 0 & 1 & 0,06250 \\
4 & 10 & 35 & 0 & 3,25 & 0,00834 \\
5 & 10 & 30 & 0 & 3 & 0,02500 \\
6 & 12 & 40 & 0 & 3 & 0,02500 \\
\hline
\end{tabular}

Table 4. Data of Coefficient Valve-Point Effect of IEEE 30 Bus 6 Generator System

\begin{tabular}{ccc}
\hline Unit & $d_{i}$ & $e_{i}$ \\
\hline 1 & 0,063 & 0,5 \\
2 & 0,098 & 0,4 \\
3 & 0 & 0 \\
4 & 0 & 0 \\
5 & 0 & 0 \\
6 & 0 & 0 \\
\hline
\end{tabular}

\subsection{IEEE 5 Bus 3 Generating System}

The simulation results of economic optimization of dispatch on IEEE 5 bus 3 generating system are shown in Table 5 . To get the optimum value, simulation is done 20 times. From Table 5 it can be seen that in the case of economic dispatch, the loading of 150 
MW on the IEEE 5 bus 3 generating system yields a minimum total cost of $\$ 2172.161804 \$ / \mathrm{h}$. The optimum cost is achieved at the 235th iteration. Furthermore, in case of economic dispatch with the valve-point effect, the total cost of minimum generation is $\$ 2187.763960 / \mathrm{h}$. This minimum cost is achieved at the 550th iteration. To generate the minimum cost of generation in the case of economic dispatch with valve-point effect resulted in a combination of the optimal output power of each generating unit of $49.371 \mathrm{MW}, 73.158 \mathrm{MW}$, and 30,019 MW with a total loss of transmission power of $2.5490 \mathrm{MW}$. The convergence of the above case iterations can be seen in Figures 4 and 5.

Table 5. Optimization Results of Economic Dispatch Simulation on the IEEE 5 bus 3 Generating System

\begin{tabular}{lll}
\hline Unit power output & Economic dispatch & $\begin{array}{l}\text { Economic dispatchwith } \\
\text { valve-point loading effect }\end{array}$ \\
\hline P1 (MW) & 47.527 & 49.371 \\
P2 (MW) & 75.441 & 73.158 \\
P3 (MW) & 29.569 & 30.019 \\
Total P-Loss $(\mathrm{MW})$ & 2.5385 & 2.5490 \\
Total Generation cost $(\$ / \mathrm{h})$ & 2172.161804 & 2187.763960 \\
\hline
\end{tabular}

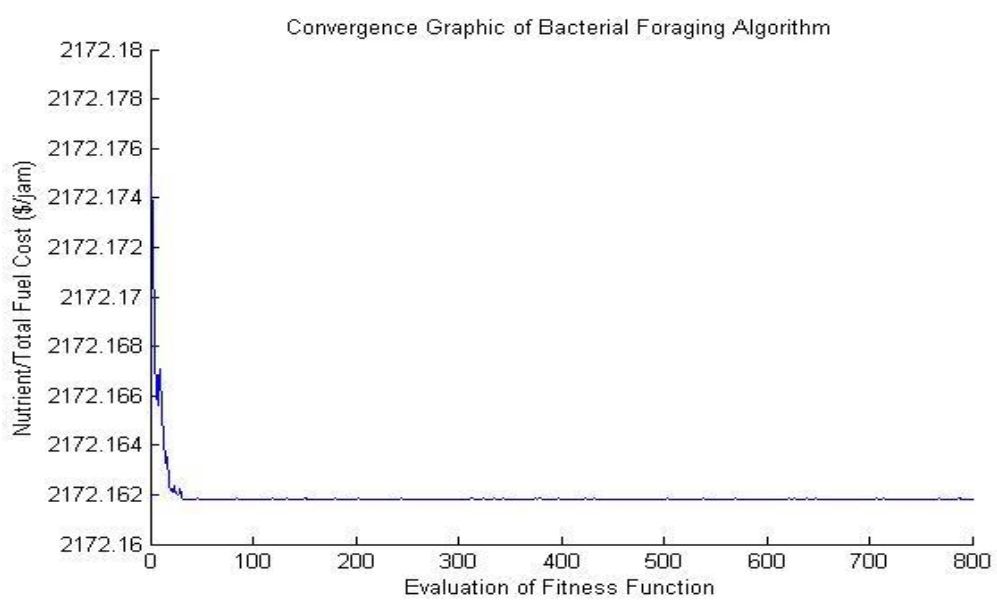

Figure 4. Characteristics of BFA convergence on IEEE 5 bus 3 generating system, case of economic dispatch

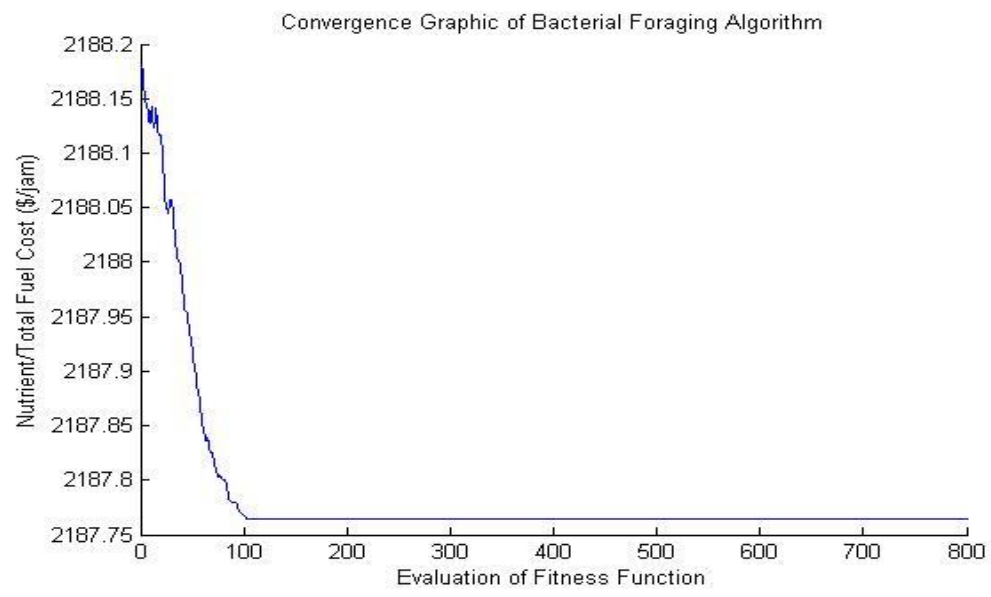

Figure 5. Characteristic of BFA convergence on IEEE 5 bus 3 generating system, economic dispatch case with valve-point effect 
So when compared to the value of the minimum cost of power generation in the case of economic dispatch in Table 5 of the case of economic dispatch with valve-point effect, it can be seen that there is a minimum cost difference between the two cases. The value of the minimum power generation cost in the case of economic dispatch with the valve-point effect is greater than the case of the economic dispatch only. The second difference is $15.602156 \$ / \mathrm{h}$. This happens because the opening of multi valve steam turbine valves produces a ripple effect (ripple) as in the generator's heat rate curve.

\subsection{IEEE 30 Bus 6 Generating System}

The optimization results of economic dispatch simulation on the IEEE 30 bus 6 generating system are shown in Table 6 . To obtain the optimum value, simulation is also done 20 times. From Table 6 it can be seen that in the case of economic dispatch of the IEEE 30 bus 6 generating system with a total load of $283.4 \mathrm{MW}$ resulting in a total minimum generation cost of $802.378984 \$ / \mathrm{h}$. The optimum cost was achieved at the 311 th iteration. Furthermore, in case of economic dispatch with valve-point effect yields total minimum generation cost of $802.454866 \$ / \mathrm{h}$. This minimum cost is achieved at the 375 th iteration. Furthermore, to generate the minimum cost of generation in the case of economic dispatch with valve-point effect to produce the optimal output power combination of each generating unit of $176,702 \mathrm{MW}, 48,817$ MW, 21,488 MW, 21,721 MW, 12,188 MW and 12,000 MW with total loss of transmission power equal to $9,5161 \mathrm{MW}$. The convergence of the above case iterations can be seen in Figure 6 and Figure 7.

Table 6. The Results of Economic Dispatch Optimization Simulation with Valve-point Effect on IEEE 30 Bus 6 Generating System

\begin{tabular}{lll}
\hline \multicolumn{1}{c}{ Unit power output } & Economic Dispatch & $\begin{array}{l}\text { Economic dispatch with valve-point } \\
\text { loading effect }\end{array}$ \\
\hline P1 (MW) & 176.648 & 176.702 \\
P2 (MW) & 48.839 & 48.817 \\
P3 (MW) & 21.496 & 21.488 \\
P4 (MW) & 21.735 & 21.721 \\
P5 (MW) & 12.195 & 12.188 \\
P6 (MW) & 12.000 & 12.000 \\
Total P-Loss (MW) & 9.5126 & 9.5161 \\
Total generation cost $(\$ / h)$ & 802.378984 & 802.454866 \\
\hline
\end{tabular}

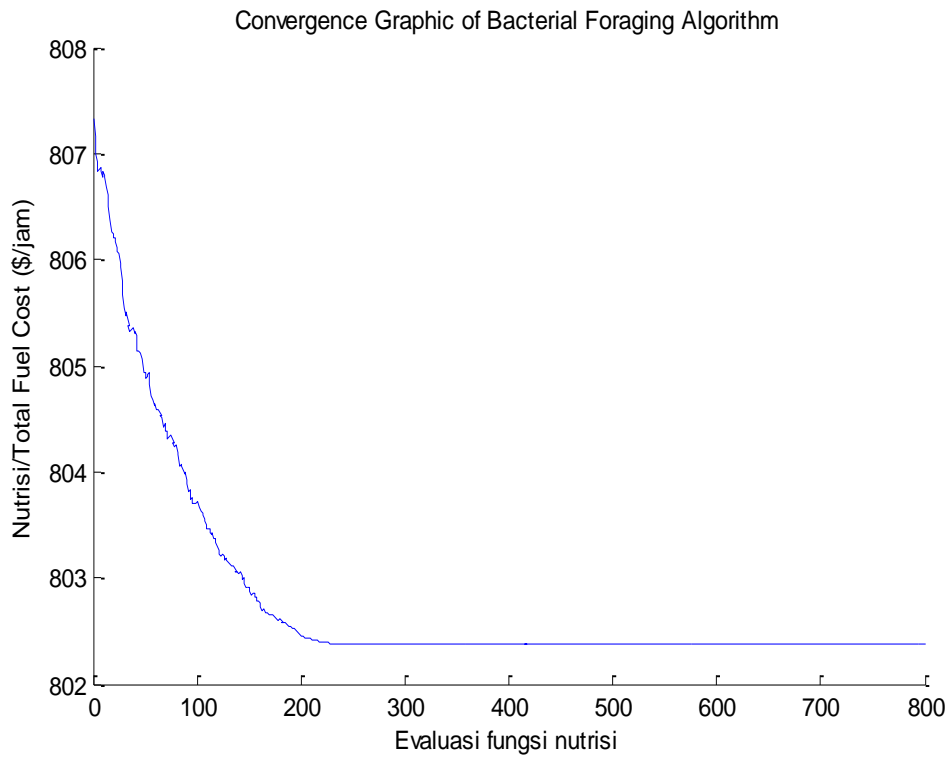

Figure 6. Characteristics of BFA convergence on IEEE 30 bus 6 generating system, case of economic dispatch 


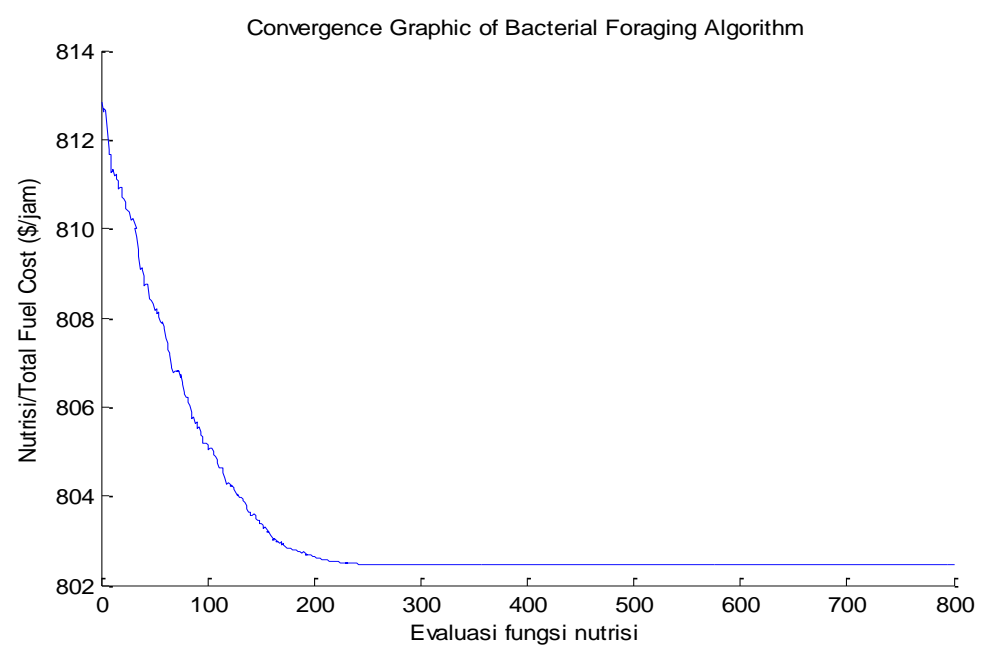

Figure 7. Characteristics of BFA convergence on IEEE 30 bus 6 generating system, economic dispatch case with valve-point effect

Thus, when compared to the value of mimimum cost of power generation in the case of economic dispatch in Table 6 cases economic dispatch with valve-point effect it can be seen that there is a minimum cost difference between the two cases. The value of the minimum power generation cost in the case of economic dispatch with the valve-point effect is greater than the case of the economic dispatch only. The difference of both values is $0.075882 \$ / \mathrm{h}$. This happens because the opening of multi valve steam turbine valves produces a ripple effect (ripple) as in the generator's heat rate curve.

\section{Conclusion}

From the results of the simulation that has been done, bacterial foraging algorithm managed to show effectiveness on the problem of economic dispatch. In the case of economic dispatch with the valve-point effect, the cost of power generation is greater because the opening of the multi valve steam turbine valve creates a ripple effect such as the generator heat rate curve.

\section{References}

[1] Balamurugan R, Subramanian S. An Improved Dynamic Programming Approach to Economic Power Dispatch with Generator Constraints and Transmission Losses. Journal of Electrical Engineering \& Technology. 2008; 3(3): 320-330

[2] Alsumait J S, Sykulski J K, Al-Othman AK. A hybrid GA-PS-SQP method to solve power system valve-point economic dispatch problems. Jurnal Applied Energy. 2009:1-9.

[3] Hossein Shahinzadeh, Sayed Mohsen Nasr-Azadani, Nazereh Jannesari. Applications of Particle Sawrm Optimization Algaorithm to Solving the Economic Load Dispatch of Units in Power Systems with Valve-Point Effects. International Journal of Electrical and Computer Engineering (IJECE). 2014; 4: 858-867.

[4] MW Mustafa, Abdirahman M Abdilahi, M Mustapha. Chaos-Enhanced Cuckoo Search for Economic Dispatch with Valve Point Effects. TELKOMNIKA (Telecommunication Computing Electronics and Control). 2016; 14: 1220-1227.

[5] SK Gachhayat, Saroj Kumar Dash, Priyambada Ray. Multi Objective Directed Bee Colony Optimization for Economic Load Dispatch With Enhanced Power Demand and Valve Point Loading. International Journal of Electrical and Computer Engineering (IJECE). 2017; 7: 2382-2391.

[6] Hota PK, Barisal AK, Chakrabarti R. Economic emission load dispatch through fuzzy based bacterial foraging algorithm. Electrical Power and Energy Systems. 2010: 1-10.

[7] Fauzi MR. Solution of Economic Dispatch Problem Using Bacterial Foraging Algorithm. Proceeding $2^{\text {nd }}$ APTECS, International Seminar on Applied Technology, Science, and Arts, ITS Surabaya. 2010: $1-5$. 
[8] Mohd Noor Abdullah, Ab Halim Abu Bakar, Nasrudin Abd Rahim, Hazlie Moklis. Economic load dispatch with nonsmooth cost functions using evolutionary particle swarm optimization. IEEJ Transactions on Electrical and Electronic Engineering. 2013 ; 8(S1): S30-S37.

[9] G Chandrakala, V Ramakrishna, Shaik JB. "Solving economic dispatch with valve point loading effects by using optimization techniques". International Journal of Scientific and Research Publications. 2012; 2(12): 45-52.

[10] NA Rahim, AHA Bakar, H Mokhlis, MN Abdullah, HA Illias, JJ Jamian. Efficient Evolutionary Particle Swarm Optimization Approach for Nonconvex Economic Load Dispatch Problem. Przeglad Elektrotechniczny. 2013; 89: 139-143.

[11] Abido MA. "Multiobjective Evolutionary Algorithms for Electric Power Dispatch Problem". IEEE. 2006; 10(3): 315-329.

[12] Passino KM. Biomimicry of Bacterial Foraging for Distributed Optimization and Control.IEEE Control Systems Magazine. 2002: 3-9.

[13] Saadat H. Power System Analysis. McGraw-Hill, New York. 1999. 